\title{
Role of multidetector CT virtual cystoscopy compared to conventional cystoscopy in the diagnosis of urinary bladder neoplasms
}

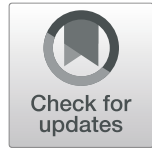

\author{
Gamal Niazi and Waleed M. Hetta* (D)
}

\begin{abstract}
Background: The study was done to assess the utility of multidetector $C T$ virtual cystoscopy versus conventional cystoscopy in the diagnosis of urinary bladder tumors. Thirty patients were included, 23 patients with recently diagnosed bladder masses, 7 patients with history of previously resected bladder masses. Conventional cystoscopy was done to all patients with biopsy of suspicious lesions. CT examinations were performed with a 16 and a 320MDCT scanners. Multiplanar reconstructed (MPR) images were obtained. Also virtual cystoscopic images were obtained with the volume rendering technique and the same software used for MPR images.

Results: CTVC detected 9 out of 10 polypoid masses detected by conventional cystoscopy ( $90 \%$ sensitivity), 23 out of 23 sessile masses (100\% sensitivity), 4 out of 4 areas of wall thickening (100\% sensitivity), and 0 out of 1 case mucosal color change ( $0 \%$ sensitivity).

Conclusion: CTVC is a minimally invasive technique that can be of value for primary diagnosis, surveillance and screening of urinary bladder neoplasms.
\end{abstract}

Keywords: $C T$ virtual cystoscopy, Urinary bladder masses

\section{Background}

Urinary bladder cancer is the fourth most common cancer in males and the tenth most common cancer in females. It typically occurs in males aged $50-70$ years and is mostly related to smoking or occupational exposure to carcinogens [1].

Urinary bladder neoplasms can arise from any of the bladder layers. They are classified as either epithelial or non-epithelial (mesenchymal), with over 95\% being epithelial. Urothelial tumors exhibit a spectrum of neoplasia ranging from a benign papilloma through carcinoma in situ to invasive carcinoma [2].

Conventional cystoscopy represents the gold standard for diagnosis and local management of bladder carcinoma with a reported sensitivity of $87 \%$ in detecting bladder neoplasm. The most important disadvantages of conventional cystoscopy are the intense discomfort for the patient, bleeding, the high cost, and local

\footnotetext{
* Correspondence: waleed_hetta@yahoo.com

Department of Radio-diagnosis, Faculty of Medicine, Ain Shams University, Ramsis St., Abbasia, Cairo, Egypt
}

complications such as infections and mechanical lesions. Furthermore, conventional cystoscopy does not provide information about extravesical extensions of the tumor [3].

With the availability of three-dimensional (3D) computer volume-rendering techniques or virtual reality imaging, intra-luminal navigation through several hollow viscera like the colon, bronchus, stomach, and the urinary bladder has been reported in the literature. Urinary bladder may be an ideal intra-abdominal organ for virtual endoscopic navigation because of its simple luminal morphology, its small volume and the absence of peristalsis [4].

CT virtual cystoscopy is emerging as a highly promising imaging tool for the detection of urinary bladder neoplasia serving as a noninvasive technique in both staging and visualization of the bladder lesions [5].

\section{Methods}

A prospective study was performed. Our study included 30 patients, 26 males and 4 females, with ages ranging from 30 to 77 years old. 
Twenty three patients were referred with hematuria and recently diagnosed bladder mass by ultrasound or by other radiological procedures while seven patients had history of previous excision of bladder masses and came for routine follow-up.

Clinical history was taken from each patient including the main complaint, previous medications or operations and past history of bilharzial infection.

General examination and local examination of the patients were performed by a urologist and laboratory studies including urine analysis and renal function tests were performed.

Conventional cystoscopy was done to all patients with biopsy of suspicious lesions.

CT examinations were performed with a 16-MDCT scanner (Toshiba Activion 16 slice) for 5 patients, a 16MDCT scanner (GE Bright speed 16 slice) for 5 patients, and a 320-MDCT scanner (Toshiba Aquilion 320 slice) for 20 patients.

\section{Patients preparation}

- Thirteen patients underwent air-filled technique. Those patients had a risky kidney function tests or were already had a Foley's catheter inserted

- Nine patients underwent contrast filled technique, those patients had good kidney function tests or were already having a request for contrast enhanced CT scan of the abdomen and pelvis.

- Eight patients underwent both techniques for comparison and for the the possibility of extravesical invasion of the tumor or any other pathologies.

- In the air filled technique, a 12-French Foley's catheter was introduced into the urinary bladder, the bladder was then distended with $150-500 \mathrm{ml}$ of room air through the Foley's catheter (according to patient's tolerance). Bladder distension was assessed on an antero-posterior scout view of the pelvis extending from the pelvic inlet to the mid symphysis pubis.

- In the contrast-filled technique, the patient was asked to void before examination and was fasting 4 hours before the intravenous injection of contrast then 40-60 ml non-ionic low-osmolar contrast medium (omanipaque) was injected intravenously and then the patient waited till bladder distension was felt.

\section{Image acquisition}

- All patients were examined in supine position except two patients with the air filled technique who underwent acquisition in the prone position also.
- We decided to leave the Foley's catheter in place all through the examination process to re-inflate the bladder if needed.

- Scanning of the urinary bladder was done with a minimal field of view according to the following parameters: $120 \mathrm{kV}$, detector collimation $16 \times 0.75$ $\mathrm{mm}$, slice thickness $1.25 \mathrm{~mm}$, rotation time $0.5 \mathrm{~s}$. The mean tube current-time product per rotation for each scan was calculated at $156 \mathrm{mAs}$.

- The study time was 5-10 min. Bladder distension and any complications occurring during the procedure were recorded.

\section{Post processing}

- All acquired images were transferred to a nearby workstation for computer post processing (Vitrea workstation or Advantage workstation)

- All images of the pelvic series were reconstructed at $1 \mathrm{~mm}$ intervals. The urinary bladder region was scanned for $4 \mathrm{~s}$ on average, and the whole procedure time was approximately $5 \mathrm{~min}$. Transverse, coronal, and sagittal planes were used to obtain the multiplanar reconstructed (MPR). The volume rendering technique and the same software as for MPR images were also used to obtain the virtual cystoscopic images. Two minutes were the average time needed for the creation of these images and start navigation of the urinary bladder.

- The axial, virtual images and MPR were prospectively interpreted, both separately and in combination. The reformatted images were used to detect lesions at the dome and neck of the bladder, which are difficult to detect by transverse image alone. They were also used to reveal tumor invasion into adjacent organs, lymphadenopathy, or distant metastases.

- The bladder walls were divided into six segments: the anterior, posterior, superior (dome), inferior (base), right lateral, and left lateral walls. We placed the camera for virtual cystoscopy in the center of the bladder lumen and then was advanced to each of the six segments.

- The number, size, location, and morphologic features of the lesions were studied. The lesions were characterized as polypoidal masses (Fig. 1), sessile masses (Fig. 2), and areas of wall thickening (Fig. 3). Polypoidal masses refer to masses protruding into the bladder lumen and attached to the bladder wall by a narrow stalk, sessile masses refer to masses connected to the bladder wall by a broad base while wall thickening is considered when the bladder wall is elevated with no definite mass. 

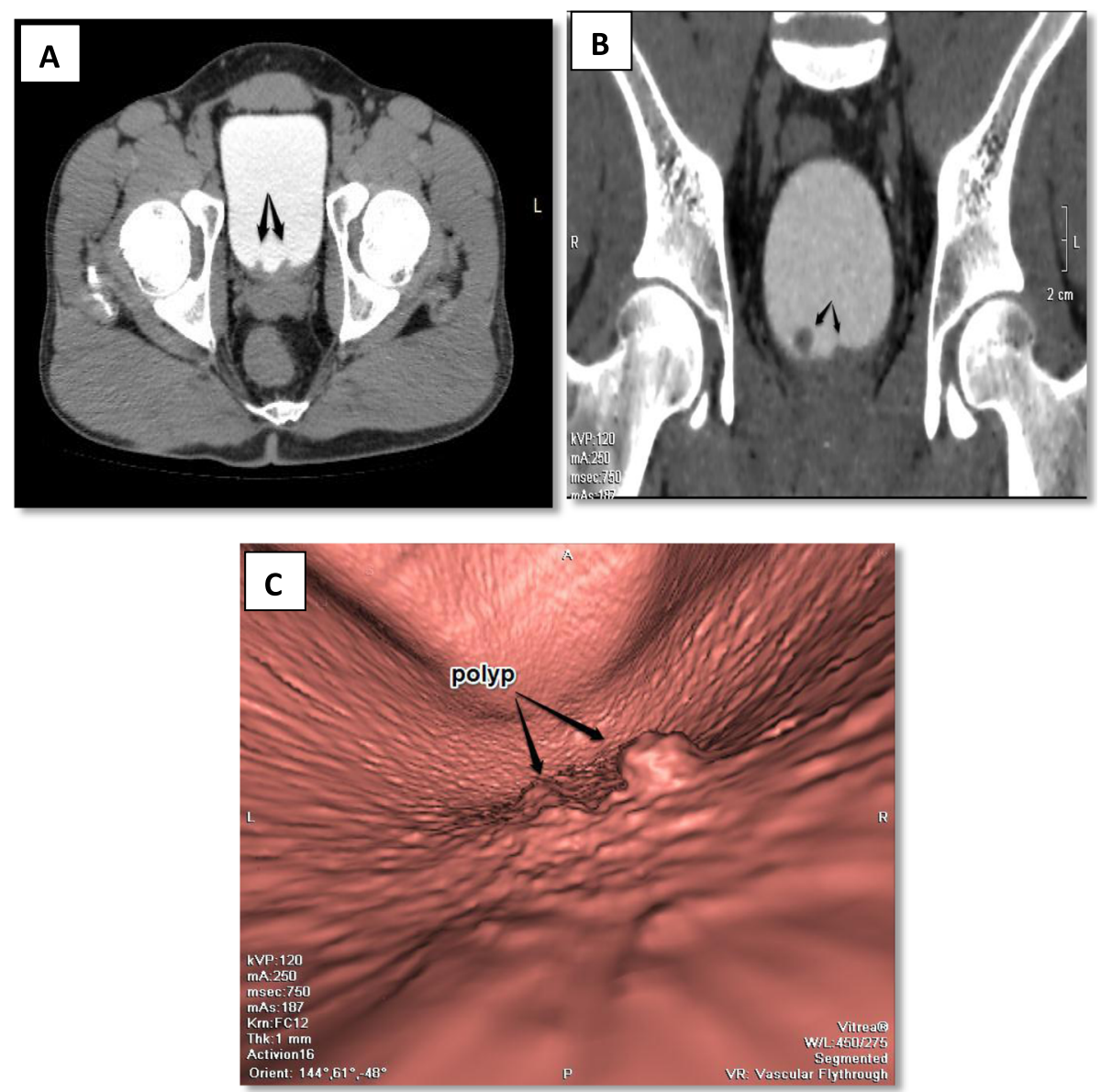

Fig. 1 a, b 47-year-old male patient presented by hematuria. 2D images showed urinary bladder basal small polypoidal masses about $(1.3 \times 1$ $\mathrm{cm})$ and $(0.5 \times 0.4 \mathrm{~cm})$ with clear perivesical fat (arrowed), no gross lymphadenopathy nor distant metastases could be detected. $\mathbf{c}$ Virtual image shows the two small polypoid masses (arrowed). Conventional cystoscopy revealed the two basal polypoidal masses with nearly the same sizes and morphology as those obtained by the virtual images, biopsy was taken and revealed noninvasive papillary transitional cell carcinoma ( $\mathrm{T} 1$ )

\section{Data analysis}

- The urologists completed detailed forms regarding number, estimated size, and location of bladder tumors found at conventional cystoscopy. Then, we compared the findings of CT virtual cystoscopy with those of conventional cystoscopy, which was considered the standard of reference. Both groups of findings were correlated with pathological diagnosis and staging.

- The 30 patients of our study were subdivided into 2 groups:

- First group (group A): 23 patients with new bladder masses (patients suggested to have new bladder masses by US or other radiological procedures.

- Second group (group B): 7 patients with recurrent bladder masses (patients with history of previous bladder tumors excision during their follow-up or after the recurrence of disease manifestations) (Fig. 4).

- Statistical analysis of the data of the present study was conducted using the paired samples $t$ test by SPSS V16. The diagnostic accuracy of VC in assessment of urinary bladder tumors regarding the (number, size, morphology, and anatomical location) was compared with conventional cystoscopy as the standard for reference through paired samples $t$ test.

- $P$ value $>0.05$ insignificant.

- $P$ value $<0.05$ significant.

- $P$ value $<0.01$ highly significant.

\section{Results}

This study included 30 patients, 26 males (86\%), and 4 females (14\%) with male to female ratio 6.14/1. The patient ages ranged from 30 years to 77 years with a mean 

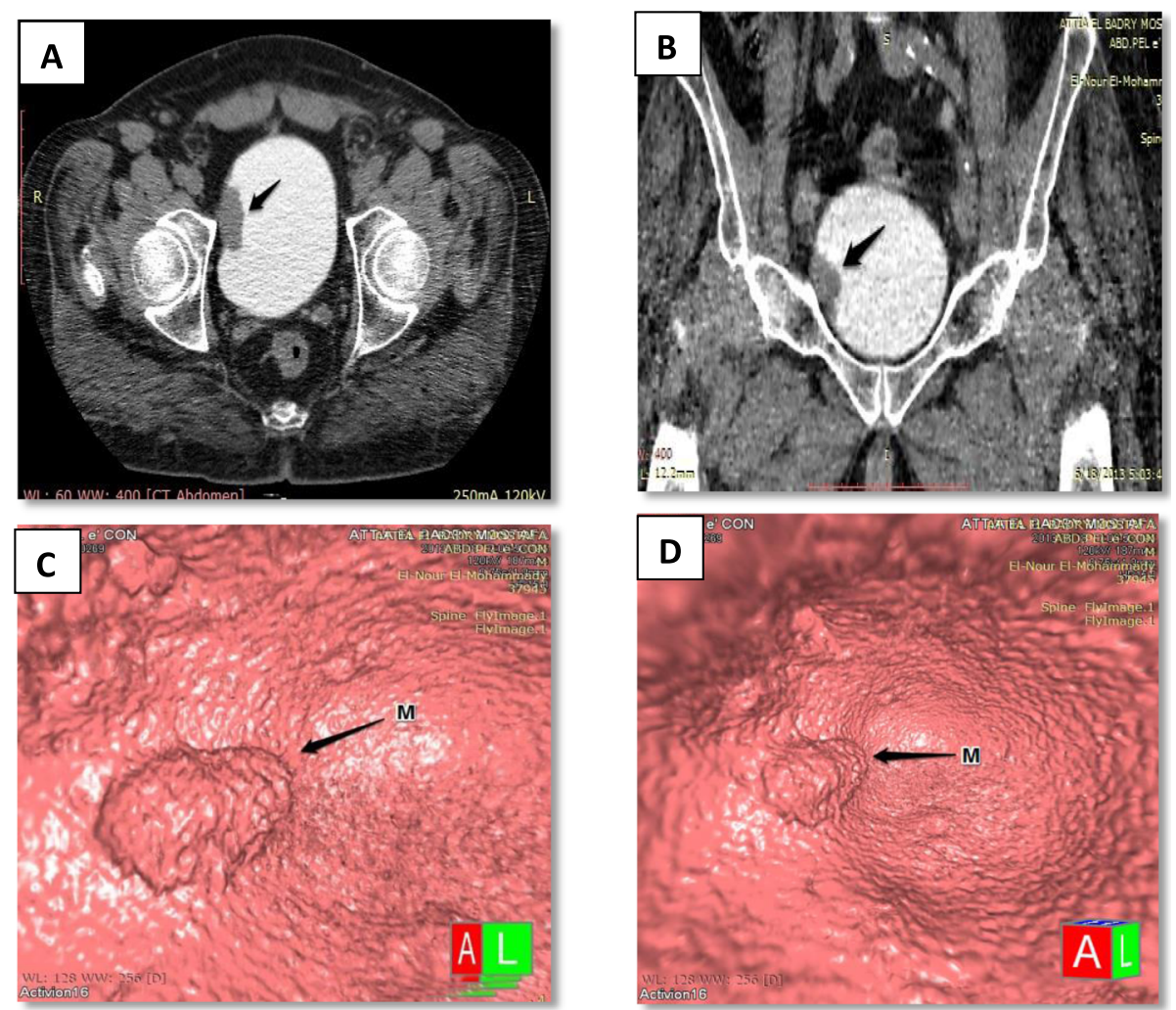

Fig. 2 a, b Male patient 51 years old presented with gross hematuria. Axia (a) and coronal (b) contrast-enhanced CT images showed right urinary bladder wall soft tissue mass (about $3 \times 2 \mathrm{~cm}$ ) with irregular lateral wall contour denoting infiltration of the muscle layer; however, the right lateral paravesical fat and lateral pelvic bony as well as muscular walls are preserved, with no sizable lymphadenopathy nor distant metastases. c, d Virtual cystoscopy images confirmed the lesion showing its clear morphology (arrowed). Conventional cystoscopy was done and revealed the right lateral wall mass with no other lesions could be detected. Biopsy was taken and revealed invasive transitional cell carcinoma

of 56.2. All patients performed conventional cystoscopy which was considered the standard of reference for assessing the efficacy of virtual cystoscopy in the detection of urinary bladder tumors and were confirmed by histopathological analysis.

In the 30 patients enrolled in the study, there were 23 patients suggested to have new bladder masses by other radiological procedures (group A); and 7 patients with history of previous bladder tumors removed through transurethral resection (TUR) during their follow-up or after the recurrence of disease manifestations (group B). Thirty-six lesions were detected by CT Virtual Cystoscopy (CTVC) in both groups; 32 plus 4 lesions respectively. There were two false negative lesions (conventional cystoscopy detected 38 lesions).

\section{First group (group A): included 23 patients with new} bladder masses

These patients had recent diagnosis of bladder tumors. Six patients underwent contrast filled technique (26.08\%) while 6 patients $(26.08 \%)$ underwent both (air and contrast filled) techniques and 11 patients had airfilled technique only (42.18\%).

\section{Second group (group B): includes 7 patients with} recurrent bladder masses (follow up patients)

Three patients underwent contrast filled technique (42.85\%) while 2 patients (28.57\%) underwent both airand contrast-filled techniques and 2 patients had airfilled technique only (28.57\%).

\section{Number of detected lesions: (Table 1)}

Thirty-six lesions were detected in the virtual images (32 in group A and 4 in group B)

- Group (A). There were (17/23 patients) "73.91\%" showing one lesion while there were (5/23 patients) "21.73\%" showing more than one lesion and $(1 / 23$ patients) "4.34\%" showing no lesions at virtual images.

- Group (B). There were (2/7 patients) "28.57\%" showing one lesion while there were (1/7 patients) "14.28\%" showing more than one lesion and (4/7 

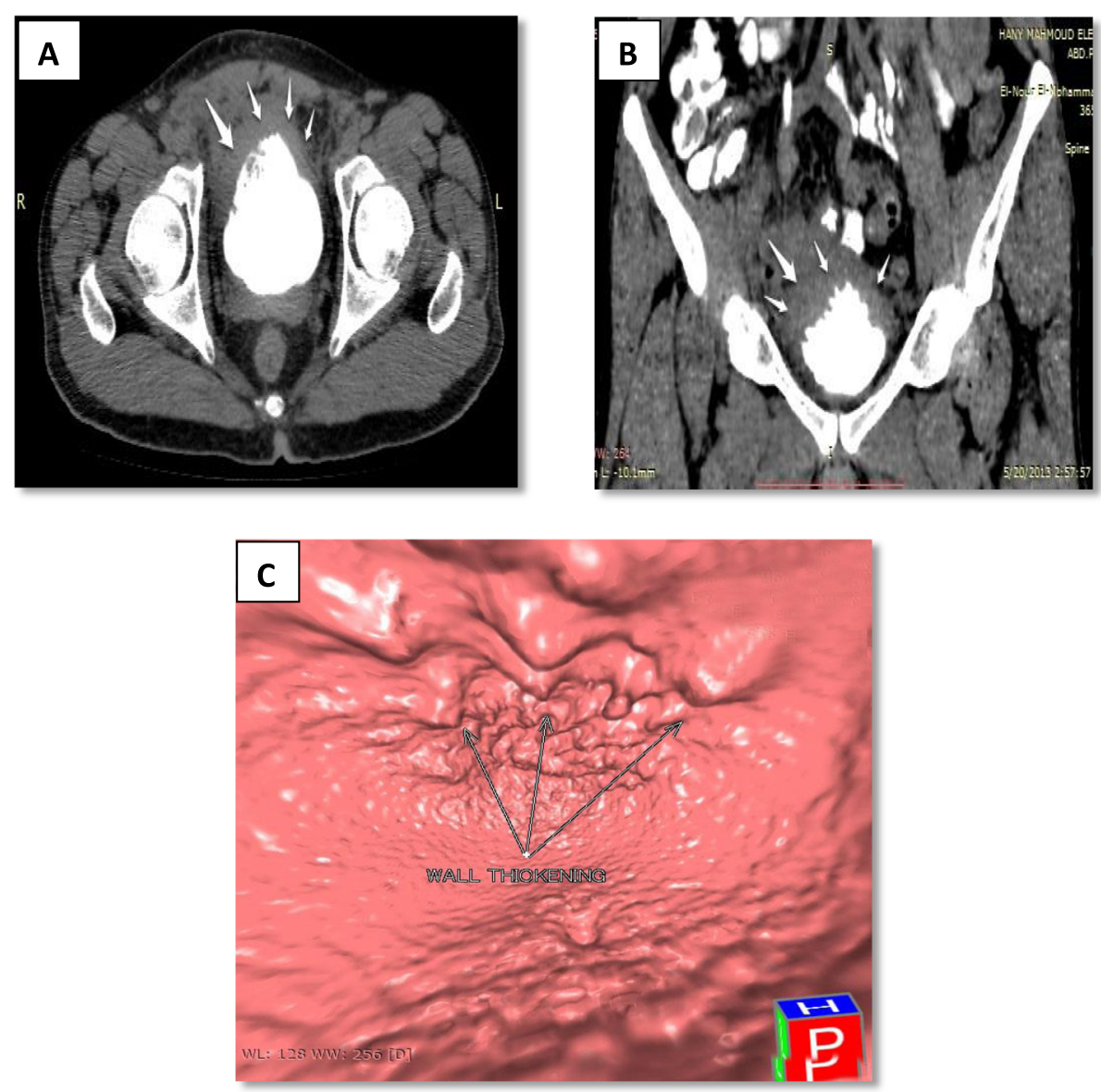

Fig. 3 a, b Male patient 48 years old presented with hematuria. Contrast-enhanced CT with axial (a) and coronal (b) images showed urinary bladder infiltrative soft tissue lesion involving the anterosuperior wall with marked irregular focal thickening and further extension to the anterosuperior perivesical fat (arrows), no enlarged lymph nodes nor distant metastases could be detected. c VC image shows clearly the wall thickening and the mucosal irregularities (arrowed). Biopsy was taken and revealed high grade transitional cell carcinoma

patients) “57.14\%" showed no lesions at virtual images.

\section{Anatomical distribution: (Table 2)}

The site of the detected lesions in different bladder walls by virtual cystoscopy is illustrated in Table 2 .

\section{Morphological appearances: (Table 3)}

The lesions detected in virtual cystoscopy were characterized as sessile mass (if the lesion has a broad base connecting it to the bladder wall), polypoid mass (if the lesion has a narrow stalk attaching it to the bladder wall) or mural thickening (when the bladder wall was elevated with no definite mass).

\section{Size of lesions (Table 4)}

The diameter of the masses (sessile and polypoid) (32 masses in both groups) detected by virtual images was ranging from 4 to $80 \mathrm{~mm}$, while the wall thickening lesions (4 lesions in both groups) were ranging from 5 to $12 \mathrm{~mm}$ at maximum thickness.

\section{Histopathological diagnosis of 38 lesions in the 30 patients (Table 5)}

\section{Side findings shown by contrast enhanced CT (axial, coronal, and sagittal images) (Table 6)}

\section{Correlation between the results of virtual cystoscopy and conventional cystoscopy}

Number of lesions: (Table 7) Conventional cystoscopy (CC) depicted 38 lesions (34 in group A and 4 in the group B), while virtual cystoscopy (VC) depicted 36 lesions (32 in group A, and 4 in group B). There was one case that shows no abnormality in both virtual and conventional cystoscopy (true negative result) and was confirmed by histopathology. 

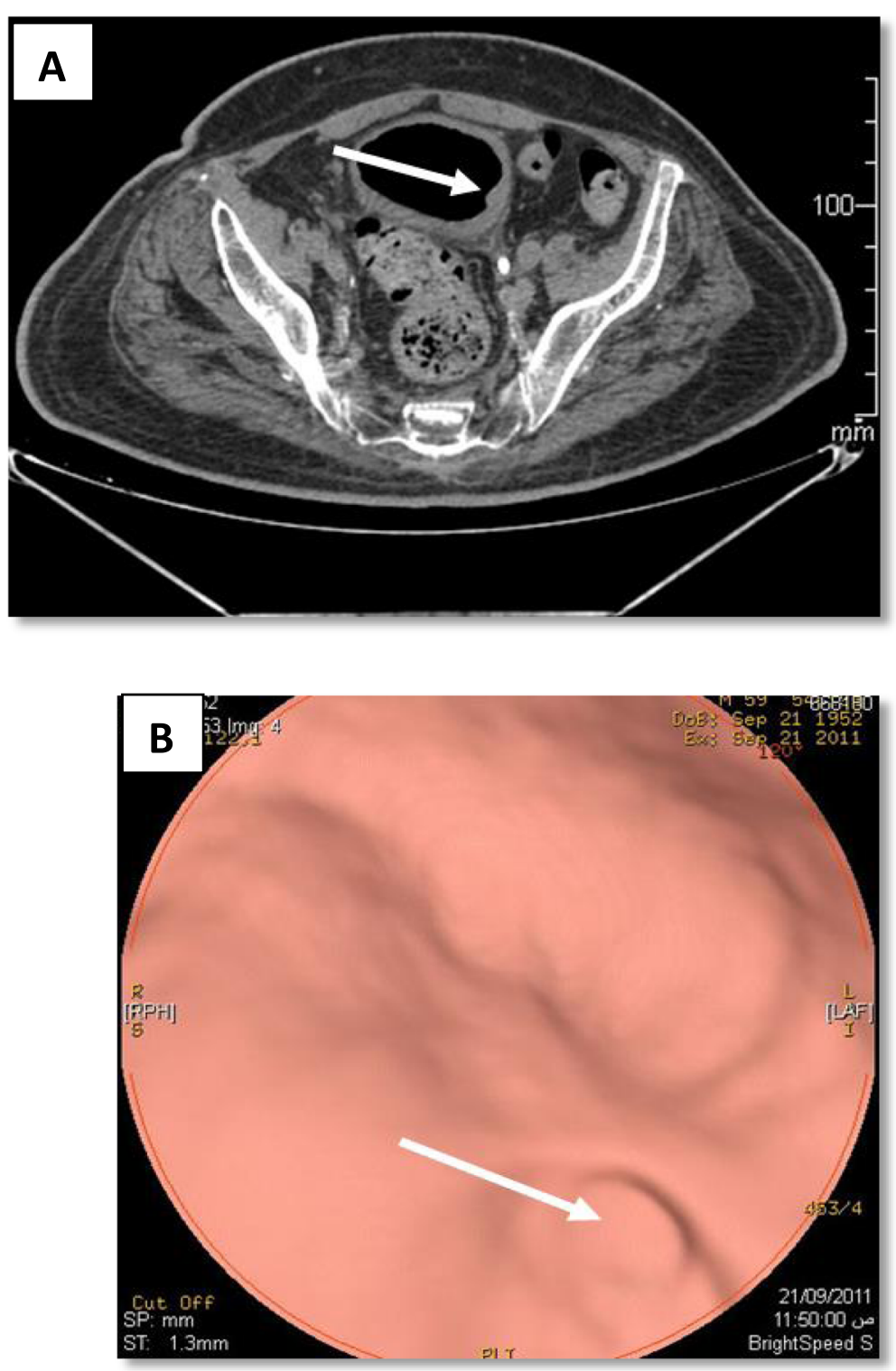

Fig. 4 a Male patient 59 years old presented with gross hematuria and history of trans-urethral resection of bladder cancer 2 years ago. Axial CT image shows circumferential mural thickening and a small left lateral wall polyp about $5 \mathrm{~mm}$. b Virtual image confirmed the thickened wall seen by axial images. A small polypoidal mass (arrowed) $4-5 \mathrm{~mm}$ can also be seen. Biopsy taken and revealed squamous cell carcinoma grade I

Out of the 38 lesions seen in conventional cystoscopy, virtual cystoscopy missed two lesions; the first lesion was a mucosal color change in the UB wall and the second was a small polypoid mass (less than $5 \mathrm{~mm}$ ) in the bladder base and the lesions were confirmed to be

Table 1 The number of detected lesions in both groups

\begin{tabular}{lll}
\hline Number of lesions & $\begin{array}{l}\text { Number of patients in } \\
\text { group }(A)\end{array}$ & $\begin{array}{l}\text { Number of patients in } \\
\text { group (B) }\end{array}$ \\
\hline Single lesion & $17 / 23$ & $2 / 7$ \\
More than one lesion & $5 / 23$ & $1 / 7$ \\
No lesions detected & $1 / 23$ & $4 / 7$ \\
\hline
\end{tabular}

carcinoma in situ (CIS) and transitional cell carcinoma (TCC) respectively by histopathology. These two false negative cases were examined with a 16-MDCT scanner.

Size of the lesions: (Table 8) Concerning the size of the lesions, the sensitivity of $\mathrm{VC}$ in detection of the masses $>5 \mathrm{~mm}$ was $100 \%$, while those masses of $\leq 5 \mathrm{~mm}$ its sensitivity was $66.6 \%$

Morphology of the lesion: (Table 9) As regards the morphology of the bladder lesions, the sensitivity of the $\mathrm{VC}$ in detection of polypoid masses was $91.6 \%$ as it missed minute polyps (less than $5 \mathrm{~mm}$ ), the VC 
Table 2 The localization of the detected lesions in different bladder walls by virtual cystoscopy

\begin{tabular}{lll}
\hline Tumor localization & $\begin{array}{l}\text { Number of lesions in } \\
\text { VC group (A) }\end{array}$ & $\begin{array}{l}\text { Number of lesions in } \\
\text { VC group (B) }\end{array}$ \\
\hline Base & 10 & 1 \\
Dome and Anterior wall & 6 & 1 \\
Posterior wall & 5 & 0 \\
Right lateral wall & 4 & 0 \\
Left lateral wall & 4 & 1 \\
Circumferential wall & 2 & 1 \\
thickening & & \\
Intradiverticular & 1 & 0
\end{tabular}

sensitivity in detection of the sessile masses or wall thickening was (100\%), while VC sensitivity in detection of urinary bladder mucosal color changes was $(0 \%)$ as the only one lesion of mucosal color changes in our study was missed and confirmed to be carcinoma in situ by conventional cystoscopy and histopathology.

Anatomical distribution: (Table 10) Concerning the anatomical distributions of the lesions the sensitivity of $\mathrm{VC}$ in detection of bladder base lesions was 93\%, while it was $100 \%$ in lesions at the dome, anterior wall, posterior wall, right lateral wall, left lateral wall, and intra-diverticular.

\section{Discussion}

Painless hematuria is one of the typical signs of bladder cancer, and one of the most important problems with urinary bladder tumors is disease recurrence. Therefore, close monitoring of the patient is required [6].

$\mathrm{CT}$ is the usually recommended radiologic approach to assess hematuria, and for CT to depict even small bladder lesions, optimal imaging conditions including adequate bladder distention and thin-slice scanning must be fulfilled [7].

According to Cohan et al. 2009, small urinary bladder lesions that are located at the bladder base (near the prostate and urethra) are difficult or impossible to be

Table 3 The number of lesions according to their morphological description

\begin{tabular}{llll}
\hline Morphological appearance & $\begin{array}{l}\text { Number of } \\
\text { lesions in VC } \\
\text { (group A) }\end{array}$ & $\begin{array}{l}\text { Number of } \\
\text { lesions in VC } \\
\text { (group B) }\end{array}$ & $\%$ \\
\hline Polypoidal mass & 7 & 1 & 22.2 \\
Sessile mass & 18 & 1 & 52.7 \\
$\begin{array}{l}\text { Wall thickening } \\
\begin{array}{l}\text { Polypoidal mass with wall } \\
\text { thickening }\end{array}\end{array}$ & 1 & 2 & 13.8 \\
$\begin{array}{l}\text { Sessile mass with wall } \\
\text { thickening }\end{array}$ & 3 & 0 & 2.7 \\
\hline
\end{tabular}

Table 4 The number of masses according to their size

\begin{tabular}{llll}
\hline Size & Group $(\mathrm{A})$ & Group $(\mathrm{B})$ & Percentage \\
\hline $5 \mathrm{~mm}$ or less & 3 & 0 & 8.3 \\
$5: 10 \mathrm{~mm}$ & 2 & 1 & 8.3 \\
More than $10 \mathrm{~mm}$ & 24 & 2 & 72.2 \\
\hline
\end{tabular}

distinguished from prostatic enlargement or periurethral tissue. Accordingly, in patients with hematuria, negative findings on CT warrant performance of conventional cystoscopy [8].

For assessing the urinary bladder tumors, the goldstandard of current diagnosis, as well as follow-up is the rigid/flexible cystoscopy [9]. Patients with urinary bladder masses should undergo interval cystoscopy to detect disease recurrence which is recommended at 3 months intervals for the first year, 6 months for the second year and annually thereafter [10].

The most significant problems encountered in conventional cystoscopy are the intense discomfort for the patient and bleeding; furthermore, the high cost, invasive nature, and local complications such as infections. Additionally, conventional cystoscopy does not provide information about extravesical extension of the tumor [3].

Urinary bladder may be an ideal intra-abdominal organ for virtual endoscopic navigation because of its simple luminal morphology, its small volume and the absence of peristalsis [4]. In this study, we tried to assess the utility of virtual cystoscopy in diagnosis of new and recurrent bladder tumors compared to conventional cystoscopy.

Fletcher and Luboldt, 2000 pointed out that the higher resolution inherent to $\mathrm{CT}$, results in a better quality of the endoluminal view. And that is why the introduction of multidetector CT (MDCT) scanners was a major technologic advance because it substantially improved $z$-axis (longitudinal) resolution by reducing section collimation and facilitating detection of very small lesions [11, 12].

In our study, we used the volume rendering technique for image processing, this was in agreement with most of the authors who preferred using this technique which provides an excellent mucosal and lesion details.

Table 5 The number of lesions according to their histopathological results

\begin{tabular}{lll}
\hline Tumor pathology & $\begin{array}{l}\text { Number (no.) of } \\
\text { lesions }\end{array}$ & $\begin{array}{l}\text { Percentage from } \\
\text { total }\end{array}$ \\
\hline TCC & 25 & 65.7 \\
SCC & 8 & 21 \\
$\begin{array}{l}\text { Benign inflammatory lesions } \\
\text { (1 polypoid mass and 2 wall } \\
\text { thickenings) }\end{array}$ & 4 & 10.5 \\
Hematoma & 1 & \\
\hline
\end{tabular}


Table 6 The side findings as revealed by the MPR images

\begin{tabular}{ll}
\hline Side findings & No. of patients \\
\hline Regional lymph nodes & 1 \\
Metastasis & 0 \\
UB diverticulum & 3 \\
Renal cysts & 4 \\
Hydrouretronephrosis & 6 \\
Prostatomegaly & 3 \\
Local extension to sigmoid colon & 1 \\
Local extension to prostate and seminal vesicles & 2 \\
\hline
\end{tabular}

The results of Hopper et al. 2000 study strongly support volume rendering for CT virtual reality, with the transition zone (mucosa) reconstructed as a separate structure [13].

Also Allan, 2001 and Tsampolus et al. 2008 found that the use of volume rendering algorithms provides a more accurate representation of tissue morphology than surface-shaded display as volume rendered images are data-rich using all available computed tomography data for reconstruction and the resultant images having fewer smoothing and blurring artifacts and this will help detecting more small lesions $[14,15]$.

In our study, 25 out of $38(65.7 \%)$ of bladder lesions were transitional cell carcinoma, squamous cell carcinoma ranked second ( 8 out of $38 ; 21 \%$ ), followed by benign inflammatory lesions (4 out of $38 ; 10.5 \%)$ and blood clot (hematoma) (1 out of $38 ; 2.6 \%$ ). Moreover, there were 7 cases $(23.3 \%)$ with history of bilharziasis among the 30 cases included in our study.

The results of previous studies stated that virtual cystoscopy allows the accurate assessment of localization and morphology of bladder masses $[2,15]$.

In our work, CTVC detected 9 out of 10 polypoid masses detected by conventional cystoscopy ( $90 \%$ sensitivity), 23 out of 23 sessile masses (100\% sensitivity), 4 out of 4 areas of wall thickening (100\% sensitivity), 0 out of 1 case mucosal color change ( $0 \%$ sensitivity).

Table 7 Comparison between CC and VC and their sensitivity and specificity regarding the number (No) of lesions detected in both patient groups

\begin{tabular}{|c|c|c|c|c|}
\hline \multirow{2}{*}{$\begin{array}{l}\text { Technique } \\
\text { No. of lesions }\end{array}$} & \multirow[t]{2}{*}{ CC } & \multirow[t]{2}{*}{ VC } & \multicolumn{2}{|l|}{$t$ test } \\
\hline & & & $t$ & $p$ value \\
\hline $\begin{array}{l}\text { No. of lesions in } \\
\text { group A }\end{array}$ & 34 & 32 & -0.814 & $\begin{array}{l}0.420 \text { NS } \\
\text { (non-significant) }\end{array}$ \\
\hline $\begin{array}{l}\text { No. of lesions in } \\
\text { group B }\end{array}$ & 4 & 4 & & \\
\hline Total no. of lesions & $38 / 38$ & $36 / 38$ & & \\
\hline Sensitivity & $100 \%$ & $94.7 \%$ & & \\
\hline Specificity & $100 \%$ & $100 \%$ & & \\
\hline
\end{tabular}

N.B. non-sign. $>0.05$, Sign. $<0.05$, High, sign. $<0.001$
Table 8 Comparison between the sensitivity of the CC and VC as regards the size of the masses

\begin{tabular}{|c|c|c|c|c|c|}
\hline \multirow{2}{*}{$\begin{array}{l}\text { Size } \\
\text { technique }\end{array}$} & \multirow{2}{*}{$\begin{array}{l}\text { Masses } \\
\leq 5 \mathrm{~mm}\end{array}$} & \multirow{2}{*}{$\begin{array}{l}\text { Masses } \\
>5 \mathrm{~mm}\end{array}$} & \multirow[t]{2}{*}{ Sensitivity } & \multicolumn{2}{|l|}{$t$ test } \\
\hline & & & & $\bar{t}$ & $p$ value \\
\hline $\mathrm{CC}$ & 3 & 30 & $100 \%$ & \multirow[t]{2}{*}{-1.00} & \multirow{2}{*}{$\begin{array}{l}0.322 \\
\text { NS } \\
\text { (non-significant) }\end{array}$} \\
\hline VC & 2 & 30 & $66.6 \%$ & & \\
\hline
\end{tabular}

N.B. non-sign. $>0.05$, Sign. $<0.05$, High, sign. $<0.001$

Concerning the size of the mass, two studies by Kim et al. 2002 and Tsili et al. 2004 were performed with a single-detector CT scanner, and a volume-rendering technique for creation of virtual images was used. The first study found that 15 (88\%) out of 17 lesions smaller than $0.5 \mathrm{~cm}$ at conventional cystoscopy, were detected on virtual cystoscopy [7].

In the second study, all bladder lesions (30) seen on conventional cystoscopy were detected on CT virtual cystoscopy (CTVC), including four patients with lesions smaller than $5 \mathrm{~mm}$ [16].

Sixtenn multi-detector CT (MDCT) cystoscopy was used in Tsampoulas et al. 2008 study to detect urinary bladder neoplasms. Fifty-five (96\%) of 57 lesions proven at conventional cystoscopy were detected, including 18 lesions with a diameter of $0.5 \mathrm{~cm}$ or less [15].

Teama et al. 2014 in their study used 64 MDCT and could identify (11/12) intravesical masses (less than $5 \mathrm{~mm}$ ) [17].

In our study, $16 \mathrm{MDCT}$ and $320 \mathrm{MDCT}$ were used, 36 out of 38 lesions were detected with sensitivity about (94.7\%) and specificity (100\%), there were 2 missed lesions ( 1 of less than $5 \mathrm{~mm}$ size and the other was a mucosal color change), 3 of those 38 lesions were $5 \mathrm{~mm}$ or less ( 2 could be detected by $\mathrm{VC}$ ) and were all proved with conventional cystoscopy.

Tsili et al. 2004 found that combining evaluated virtual images with axial and MPR images could provide valuable information for extraluminal disease, such as extravesical invasion, distal ureteral obstruction, and pressure of the neighboring organs [16].

Kim et al. 2005 concluded that virtual cystoscopy has many advantages over axial CT and MPR images. First, virtual cystoscopy is superior in evaluation of the mucosal surface of the bladder and therefore can detect superficial lesions missed by source CT images or MPR images. Virtual cystoscopy can help the operator to navigate the mucosal surface in various projections. Also, virtual cystoscopy provides interactive navigation, allowing the operator to make more confident decisions [18].

In our study, it was crucial to depend on both 2D and $3 \mathrm{D}$ images together for interpretation of virtual cystoscopy.

Many authors encouraging $\mathrm{VC}$ to be used as screening tests for patients with history of bladder tumor. 
Table 9 Comparison between conventional cystoscopy (CC) and virtual cystoscopy (VC) regarding the morphological description of the lesions

\begin{tabular}{llllll}
\hline Morphology & $\begin{array}{l}\text { Number of } \\
\text { lesions in CC }\end{array}$ & $\begin{array}{l}\text { CC } \\
\text { (sensitivity) }\end{array}$ & $\begin{array}{l}\text { Number of } \\
\text { lesions in VC }\end{array}$ & $\begin{array}{l}\text { VC } \\
\text { (sensitivity) (\%) }\end{array}$ & t test \\
\hline Polypoid mass & 10 & $100 \%$ & 9 & 90 & -0.586 \\
Sessile mass & 23 & $100 \%$ & 23 & 100 & 0.560 NS: \\
Wall thickening & 4 & $100 \%$ & 4 & 100 & 0 \\
Mucosal color change & 1 & $100 \%$ & 0 & 0 & \\
\hline
\end{tabular}

N.B. non-sign. $>0.05$, Sign. $<0.05$, High, sign. $<0.001$

Tsili et al. 2004 said that the technique can be proposed as a screening test for recurrent bladder cancer. A negative CT cystoscopy would limit the need for conventional cystoscopy [16].

Kawai et al. 2004 agreed that VC is a useful screening tool which can direct the surgeon to an appropriate area for biopsy. If normal, it may obviate the need for conventional cystoscopy and biopsy, and could be useful for surveillance of known tumors [19].

In our study, 7 patients with history of TURT were included 1 recurrent polyp, 2 sessile masses, 1 wall thickening, and 4 patients were free, and all were confirmed by conventional cystoscopy.

Advantages of virtual cystoscopy noticed in our study include that the technique is non- or minimally invasive, with minimal discomfort and risks for the patients, especially that there is no need for anesthesia.

Virtual cystoscopy allows accurate measurement of the dimensions of the tumor with high accuracy in detection of bladder lesions, despite its size and morphology, as well as wall thickening.

Virtual CT cystoscopy improves the value of axial CT images and allows utilization of the largest amount of CT data as combined multiplanar and virtual cystoscopy depicts both intraluminal and extraluminal pathologic changes in the same study.

CT virtual cystoscopy also helps to assess urinary bladder areas that are difficult to be assessed using conventional cystoscopy, such as the anterior bladder neck and narrow-mouthed diverticulae.
The drawbacks we met in our study include that the partially calcified masses or bladder calculi were seen only on the source images but not on virtual images due to the threshold selection optimized to depict soft tissue abnormalities.

Another disadvantage is that virtual images alone cannot make sure of the nature, or the origin of the mass either it is vesical or extravesical like enlarged median lobe of the prostate.

Also the depth of the bladder wall invasion and the exophytic components could not be diagnosed unless CT virtual cystoscopy and MPR images were used together.

Six patients had paravesical fat extension, one patient had sigmoid colon invasion and two patients had seminal vesicles and prostatic invasion, virtual cystoscopy alone cannot judge the paravesical fat nor the surrounding structures invasion, and this was important criteria in grading the bladder tumor.

CTVC is unable to detect flat lesions, which appear as subtle color changes of the mucosa on conventional cystoscopy; therefore, it cannot be used to detect carcinomas in situ.

Moreover, CTVC lacks the ability to take tissue biopsy for histopathologic assessment; an ability that is possible on conventional cystoscopy.

The differentiation between small tumors and inflammatory swelling of the mucosa could be difficult, especially in patients with unsatisfactory bladder filling. There was a patient with a minute polyp diagnosed as inflammatory lesion after $\mathrm{CC}$ and biopsy.

Table 10 Comparison between conventional cystoscopy (CC) and virtual cystoscopy (VC) and their sensitivity regarding the tumor localization

\begin{tabular}{|c|c|c|c|c|c|c|}
\hline \multirow[t]{2}{*}{ Tumor localization } & \multirow{2}{*}{$\begin{array}{l}\text { No of } \\
\text { lesions in VC }\end{array}$} & \multirow{2}{*}{$\begin{array}{l}\text { VC } \\
\text { (sensitivity) (\%) }\end{array}$} & \multirow{2}{*}{$\begin{array}{l}\text { No of } \\
\text { lesions in CC }\end{array}$} & \multirow{2}{*}{$\begin{array}{l}\text { CC } \\
\text { (sensitivity) (\%) }\end{array}$} & \multicolumn{2}{|l|}{$t$ test } \\
\hline & & & & & $\mathrm{t}$ & $p$ value \\
\hline Base & 11 & 91.6 & 12 & 100 & 0.684 & \multirow{7}{*}{$\begin{array}{l}0.497 \\
\text { NS } \\
\text { (non-significant) }\end{array}$} \\
\hline Dome and Anterior wall & 7 & 100 & 7 & 100 & & \\
\hline Posterior wall & 5 & 100 & 5 & 100 & & \\
\hline Right lateral wall & 4 & 100 & 5 & 100 & & \\
\hline Left lateral wall & 5 & 100 & 5 & 100 & & \\
\hline Circumferential wall thickening & 3 & 100 & 3 & 100 & & \\
\hline Intradiverticular & 1 & 100 & 1 & 100 & & \\
\hline
\end{tabular}

N.B. non-sign. $>0.05$, Sign. $<0.05$, High, sign. $<0.001$ 
In addition, fibrosis induced mucosal thickening cannot be distinguished from a neoplasm. Similar problem is faced in conventional cystoscopy, because biopsy is often required to determine whether a bladder lesion is inflammatory, fibrotic, or neoplastic.

\section{Conclusion}

The results of our study suggest that CTVC cannot completely replace conventional cystoscopy. However, CTVC is an effective diagnostic tool that can depict the location and dimensions of tumors in patients with suspected urinary bladder masses. CTVC also plays a role as a follow-up examination in patients with bladder neoplasm who are under treatment.

\section{Abbreviations}

CTVC: Computed tomography virtual cystoscopy; MDCT: Multi-detector computed tomography

\section{Acknowledgements}

Not applicable

\section{Authors' contributions}

GN made the design of the work and interpretation of data. WH acquisition and analysis of data and drafted the manuscript. Both authors have read and approved the manuscript.

\section{Funding}

No funding was obtained for this study

\section{Availability of data and materials}

Data sharing is not applicable to this article as no datasets were generated or analysed during the current study.

\section{Ethics approval and consent to participate}

The study done after approval of ethical board of Ain Shams University (the reference number is not appropriate) and an informed written consent was taken from each participant in the study.

\section{Consent for publication}

Written consent for publication was taken from all participants.

\section{Competing interests}

The authors declare that they have no competing interests.

Received: 24 November 2019 Accepted: 26 November 2019

Published online: 11 December 2019

\section{References}

1. Verma S, Rajesh A, Prasad S et al (2012) Urinary bladder cancer: role of MR imaging. RadioGraphics 32(2):371-387

2. Karabacak OR, Cakmakci E, Ozturk U et al (2011 Feb) Virtual cystoscopy: the evaluation of bladder lesions with computed tomographic virtual cystoscopy. Can Urol Assoc J 5(1):34-37

3. Panebianco V, Sciarra A, Di Martino M et al (2010 June) Bladder carcinoma: MDCT cystography and virtual cystoscopy. Abdominalimaging 35(3):257-264

4. Singh I, Mehrotra G, Jaura M et al (2012) Virtual cystoscopy (pneumocystoscopy)-Its utility in the prospective evaluation of bladder tumor. Indian J Urol 28(2):164-168

5. Jinzaki M, Tanimoto A, Shinmoto $\mathrm{H}$ et al (2007) Detection of bladder tumors with dynamic contrast enhanced MDCT. AJR Am J Roentgenol. 188(4):913-918

6. Abrol S, Jairath A, Ganpule S et al (2015 Oct) Can CT virtual cystoscopy replace conventional cystoscopy in early detection of bladder cancer. Adv Urol 2015:926590
7. Kim JK, Ahn JH, Park T et al (2002) Virtual cystoscopy of the contrast material-filled bladder in patients with gross hematuria. AJR 179(3):763-768

8. Cohan RH, Caoili EM, Cowan NC et al (2009) MDCT urography,exploring a new paradigm for imaging of bladder cancer. AJR 192:1501-1508

9. Elawady H, Mahmoud MA, Mostafa D et al (2016) Computed tomography virtual cystoscopy for follow-up of patients with superficial bladder tumours in comparison to conventional cystoscopy, An exploratory study. Arab J Urol 14(3):192-197

10. Tsili AC, Giannakis D, Sofikitis N et al (2008) Advantages of multidetector CT cystoscopy in the detection of bladder tumors. Curr Med Imaging Rev 4(4): 213-221

11. Fletcher JG, Luboldt WCT (2000) Colonography and MR colonography: current status, research directions and comparison. Eur Radiol 10(5):786-801

12. Flohr TG, Schaller S, Stierstorfer $\mathrm{K}$ et al (2005) Multi-detector row CT systems and image-reconstruction techniques. Radiology 235:756-773

13. Hopper KD, lyriboz AT, Wise SW et al (2000) Mucosal detail at CT virtual reality: surface versus volume rendering. Radiology 214:517-522

14. James Allan, D.D Tolley, et al: Virtual endoscopy in urology [Review Article] Current Opinion in Urology: 2001Mar; 11(2):189-192.

15. Tsampoulas C, Tsili AC, Giannakis D, et al. 16-MDCT cystoscopy in the evaluation of neoplasms of the urinary bladder AJR.2008;190:729-735.

16. Tsili AC, Tsampoulas C, Chatziparaskevas N et al (2004) Computed tomographic virtual cystoscopy for the detection of urinary bladder neoplasms. Eur Urol 46:579-585

17. Teama AA, Darweesh AN, Abol-Enin HA (2014 Jun) Role of multidetector computed tomography virtual cystoscopy in evaluation of urinary bladder carcinoma. EJRNM 45(2):543-554

18. Kim JK, Park SY, Kim HS et al (2005) Comparison of virtual cystoscopy, multiplanar reformation, and source CT images with contrast material-filled bladder for detecting lesions. AJR Am J Roentgenol 185:689-696

19. Kawai N, Miruma T, Nagata D et al (2004) Intravenous urography-virtual cystoscopy is a better preliminary examination than air virtual cystoscopy. BJU Int 94:832-836

\section{Publisher's Note}

Springer Nature remains neutral with regard to jurisdictional claims in published maps and institutional affiliations.

\section{Submit your manuscript to a SpringerOpen ${ }^{\circ}$ journal and benefit from:}

- Convenient online submission

- Rigorous peer review

- Open access: articles freely available online

High visibility within the field

- Retaining the copyright to your article

Submit your next manuscript at $>$ springeropen.com 